\title{
Depression and Sleep Quality of Obstetricians
}

\author{
Jin Gon Bae, MD¹, Won Kyu Jang, MD¹, Yong Won Cho, MD², Keun Tae Kim, MD² \\ 'Department of Obstetrics and Gynecology, Keimyung University School of Medicine, Daegu, Korea \\ ${ }^{2}$ Department of Neurology, Keimyung University School of Medicine, Daegu, Korea
}

Received: June 24, 2020

Revised: September 5, 2020

Accepted: September 20, 2020

Correspondence

Keun Tae Kim, MD

Department of Neurology,

Keimyung University School of Medicine,

1095 Dalgubeol-daero, Dalseo-gu,

Daegu 42601, Korea

Tel +82-53-258-4379

Fax +82-53-258-4380

E-mail 6k5upa@gmail.com

ORCID

Jin Gon Bae

https://orcid.org/0000-0001-6127-162X

Won Kyu Jang

https://orcid.org/0000-0002-9675-7459

Yong Won Cho

https://orcid.org/0000-0002-6127-1045

Keun Tae Kim

https://orcid.org/0000-0002-7124-0736

(c) This is an Open Access article distributed under the terms of the Creative Commons Attribution Non-Commercial License (https://creativecommons.org/licenses/by-nc/4.0) which permits unrestricted non-commercial use, distribution, and reproduction in any medium, provided the original work is properly cited.
Background and Objective Obstetricians play a pivotal role in pregnancy and delivery. Also, they frequently encounter common comorbidity, such as pregnancy-related depression. We investigated the depression and sleep status of obstetricians in South Korea.

Methods This is a questionnaire-based cross-sectional survey, carried out from December 2019 to January 2020. We asked board-certificated obstetricians to complete a series of questionnaires, including demographic information, the Beck Depression Inventory-2 (K-BDI), Pittsburgh sleep quality index (K-PSQI), insomnia severity index, Epworth Sleepiness Scale, and an acronym Snoring, Tiredness, Observed apneas, and high blood Pressure (STOP).

Results A total of 107 obstetricians completed the questionnaires. Their mean age was $50.60 \pm$ 7.83 years, and $83(77.6 \%)$ were male. The average years after the board certification was $17.80 \pm$ 7.62 years. They worked $68.90 \pm 19.61$ hours a week, and slept for 7 hours (06:59:20.75 \pm 01:08:21.63), approximately. The number of duty days and deliveries in the last month were $6.44 \pm 4.35$ and $28.95 \pm 25.16$ per month, respectively. Forty-five (42.1\%) obstetricians had poor sleep quality, 22 (20.6\%) had suspicious insomnia, and $45(42.1 \%)$ had significant depression. In multiple regression analyses, K-PSQI (standardized $\beta=0.492, \mathrm{p}<0.001$ ) and the number of deliveries in the last month (standardized $\beta=0.453, \mathrm{p}<0.001$ ) showed significant influence upon K-BDI.

Conclusions The risk of depression increased by $8.8 \%$ as another monthly delivery was performed. A point increase in K-PSQI increased the risk of depression by $49.6 \%$. The worse the sleep quality, and the more frequent the deliveries, the more depressed the obstetrician was.

Sleep Med Res 2020;11(2):135-139

Key Words Sleep, Depression, Physicians, Obstetrics.

\section{INTRODUCTION}

It is well known that depression is more prevalent in women than in men [1], and some pregnant women suffer from depression during pregnancy, whether or not they had previously had depression [2]. Obstetricians mainly care for women, especially pregnant women. Therefore, they play a pivotal role not only in pregnancy but also in common clinical situations, such as depression during pregnancy. However, little is known about the depression of obstetricians.

One of the most widely studied issues of doctor's psychological problems is burnout syndrome [3]. A recent meta-analysis of 2617 articles, including 15 randomized trials and 37 cohort studies, reported that about half of physicians reported burnout [4]. Surgeons showed lower career satisfaction than did doctors in pediatrics or internal medicine, in addition, working hours per week is a predictor of burnout [5]. Another study of South Korean surgeons also demonstrated that more working hours led to higher occupational stress [6]. By professional subjects, there are only a few studies of obstetrics and gynecologists, and even fewer studies of only obstetricians are available. A survey of obstetricians and gynecologists in the United States reported that the prevalence of burnout syndrome ranged from $40 \%$ to $75 \%[7,8]$. Although studies have been conducted on burnout syndrome in doctors, burnout syndrome is not clas- 
sified as a medical condition by the World Health Organization [4]. It is a phenomenon rather than a disease, with no explicit mention of whether the burnout syndrome is temporary or continuous, where it comes from, or where it goes. Therefore, it has been suggested that a study of burnout syndrome should focus on depression [9-12].

Doctors' mental problems can be a major threat in terms of patient harm, legal issues, shortage of doctors, and increasing health-care costs $[13,14]$. Compared with patients, doctors are more aware of the benefits of treatment of depression, have better financial resources, and have better access to the health-care system. Nonetheless, psychological studies involving doctors are not common, since doctors tend to care for others more than for themselves, and tend to underestimate their own symptoms. Some doctors do not want to evaluate their own depression, because of the deep stigma that they too feel. For these reasons, research has recently been conducted using the more informal name of "burnout syndrome" instead of "depression." The psychiatric and sleep status of obstetricians in South Korea has never been investigated. In this regard, our aim in this study is to investigate the subjective psychiatric states, such as depression, and sleep quality, of obstetricians in South Korea.

\section{METHODS}

This is a questionnaire-based prospective cross-sectional survey, carried out from December 2019 to January 2020. The "obstetrician" in this study stands for a doctor who has been boardcertified in obstetrics and gynecology after four years of residency training and is participating in the on-call schedule as well as delivery. After an offline face-to-face interview by a neurologist, they were asked to complete a series questionnaires, including the Korean-validated version of the Beck Depression Inventory-2 (K-BDI) [15], Pittsburgh sleep quality index (K-PSQI) [16], insomnia severity index (K-ISI) [17], Epworth Sleepiness Scale (K-ESS) [18], and an acronym Snoring, Tiredness, Observed apneas, and high blood Pressure (STOP). We asked all subjects to fill out the demographic information query, including age, sex, years after the board certification, forms of employment, duty systems and shift patterns, the number of deliveries in the last month, previous illness, current medication, smoking, drinking habits, and caffeine consumption. Obstetricians with less than one year after transfer or opening the clinic were excluded from the analysis.

\section{Ethics Statement}

This study was approved by the Institutional Review Board of Keimyung University Dongsan Medical Center (DSMC 201804-003-005). All subjects provided written informed consent before enrolling in this study, in accordance with the Declaration of Helsinki.

\section{Statistical Analysis}

In order to find the risk factors of depression and poor sleep quality, we did regression analysis with variables that showed significant results in the correlation analysis. We did stepwise logistic progress analysis by adjusting the variables, and statistical analysis by using SPSS version 22.0 (IBM Corp., Armonk, NY, USA). Statistical significance was set at $\mathrm{p}<0.05$.

\section{RESULTS}

There were 158 board-certified obstetrics working in Daegu (a metropolitan city with a population of 2.5 million) and Gyeongsangbuk-do (a province with a population of 2.65 million). Of the 158,107 obstetricians participated in the study and completed the questionnaires. Their mean age was $50.60 \pm 7.83$ years, and $83(77.6 \%)$ were male (Table 1$)$. The average years after the board certification was $17.80 \pm 7.62$ years. In this study, 48 (44.9\%) of the obstetricians worked as employees, and 59 (55.1\%) had a role in the management of the hospitals. They worked $68.90 \pm$ 19.61 hours per week on average, and their average sleep time was approximately 7 hours a day (06:59:20.75 \pm 01:08:21.63). There were 84 (78.5\%) obstetricians who worked 53 hours or more each week. The average number of duty days per month and the number of deliveries in the last month were $6.44 \pm 4.35$ and $28.95 \pm 25.16$, respectively. Obstetricians who consumed more than one cup of coffee a day accounted for 94 (87.9\%), those who consumed alcohol more than once a week were 75 (70.1\%), and 38 (35.5\%) were currently smoking. The results of the series of questionnaires are shown in Table 2. Some obstetricians had already been diagnosed with a sleep disorder [ 2 of sleep

Table 1. Demographic characteristics $(n=107)$

\begin{tabular}{lc}
\hline & $\begin{array}{c}\text { Mean } \pm \text { standard } \\
\text { deviation or } \mathrm{n}(\%)\end{array}$ \\
\hline Age, year & $50.60 \pm 7.83$ \\
Sex, male & $83(77.6)$ \\
Years after the board certification, year & $17.80 \pm 7.62$ \\
Duty days per month & $6.44 \pm 4.35$ \\
Working hours per week & $68.90 \pm 19.61$ \\
Number of deliveries in the last month & $28.95 \pm 25.16$ \\
Forms of employment & \\
Salaried employee of the clinic & $46(43.0)$ \\
The owner of the clinic & $21(19.6)$ \\
Co-owner of the clinic & $38(35.5)$ \\
Faculty member of a teaching hospital & $2(1.9)$ \\
Hours of sleep, HH:MM:SS & $06: 59: 20 \pm 01: 08: 21$ \\
More than one cup of coffee a day & $94(87.9)$ \\
Alcohol ingestion more than once a week & $75(70.1)$ \\
Currently smoking & $38(35.5)$ \\
\hline
\end{tabular}


apnea, 4 of insomnia, and 10 of restless legs syndrome (RLS)]. The average scores of K-PSQI and K-ISI were $8.07 \pm 3.85$ and $9.74 \pm 6.67$, respectively. There were 45 (42.1\%) obstetricians with poor sleep quality of clinical significance (K-PSQI $\geq 8.5$ ) and 22 (20.6\%) with suspicious insomnia (K-ISI $\geq 15.5)$. The average score on the K-ESS was $8.18 \pm 4.82$, and that on the K-BDI was $15.64 \pm 11.12$. There were 45 (42.1\%) obstetricians with significant depression (K-BDI $\geq 18$ ).

Table 3 shows the result of correlation analysis. K-PSQI was associated with K-ISI ( $\mathrm{r}=0.734, \mathrm{p}<0.001)$, K-ESS ( $\mathrm{r}=0.501$, $\mathrm{p}<0.001)$, hours of sleep $(\mathrm{r}=-0.434, \mathrm{p}<0.001)$, days of duty per month $(\mathrm{r}=0.432, \mathrm{p}<0.001)$, total working hours per week $(\mathrm{r}=0.431, \mathrm{p}<0.001)$, number of deliveries in the last month $(\mathrm{r}=$ $0.374, \mathrm{p}<0.001)$, STOP $>2(\mathrm{r}=0.300, \mathrm{p}=0.002)$, and presence of RLS $(\mathrm{r}=0.192, \mathrm{p}=0.048)$. K-BDI was associated with K-ISI $(\mathrm{r}=0.704, \mathrm{p}<0.001)$, K-ESS $(\mathrm{r}=0.682, \mathrm{p}<0.001)$, number of deliveries in the last month $(\mathrm{r}=0.610, \mathrm{p}<0.001)$, hours of sleep $(\mathrm{r}=$ $-0.439, \mathrm{p}<0.001)$, STOP $>2(\mathrm{r}=0350, \mathrm{p}<0.001)$, days of duty per month $(\mathrm{r}=0.347, \mathrm{p}<0.001)$, total working hours per week $(\mathrm{r}=0.341, \mathrm{p}<0.001)$, and presence of RLS $(\mathrm{r}=0.315, \mathrm{p}=0.001)$.

We did multiple regression analyses to find the factors that influence K-BDI. In Table 4, the multiple regression model, K-PSQI (standardized $\beta=0.492, \mathrm{p}<0.001$ ), shows that the number of deliveries in the last month (standardized $\beta=0.453, \mathrm{p}<0.001$ ) had significant positive regression weights. In the multiple regression analyses of K-PSQI, K-BDI had significant positive regression weights (standardized $\beta=0.661, \mathrm{p}<0.001$ ) (Table 5). In the multivariate logistic regression of $\mathrm{K}-\mathrm{BDI}$, the risk of depression $(\mathrm{K}-\mathrm{BDI} \geq 18)$ increased by 1.088 times as the number

Table 2. Results of questionnaires $(n=107)$

\begin{tabular}{lc}
\hline & Mean \pm standard deviation or $\mathrm{n}(\%)$ \\
\hline Previous illness & $40(37.4)$ \\
Medication & $35(32.7)$ \\
Ready-diagnosed sleep disorder & \\
$\quad$ Sleep apnea & $2(0.9)$ \\
$\quad$ Insomnia & $4(3.7)$ \\
$\quad$ Restless legs syndrome & $10(9.3)$ \\
K-PSQI & $8.07 \pm 3.85$ \\
K-PSQI $\geq 8.5$ & $45(42.1)$ \\
K-ISI & $9.74 \pm 6.67$ \\
K-ISI $\geq 15.5$ & $22(20.6)$ \\
K-ESS & $8.18 \pm 4.82$ \\
STOP $>2$ & $66(61.7)$ \\
K-BDI & $15.64 \pm 11.12$ \\
K-BDI $\geq 18$ & $45(42.1)$ \\
\hline
\end{tabular}

K-: Korean version of, PSQI: Pittsburg sleep quality index, BDI: Beck Depression Inventory-2, ISI: insomnia severity index, ESS: Epworth Sleepiness Scale, STOP: an acronym Snoring, Tiredness, Observed apneas, and high blood Pressure. of deliveries in the last month increased by 1 , and the risk of depression increased by 1.496 times as the K-PSQI increased by 1 point (Table 6). Conversely, in the multivariate logistic regression of K-PSQI, the risk of poor sleep quality (K-PSQI $\geq 8.5$ ) increased by 1.156 times as K-BDI increased by 1 point (Table 7).

Table 3. Correlation analysis

\begin{tabular}{|c|c|c|c|c|}
\hline \multirow{2}{*}{ Variables } & \multicolumn{2}{|c|}{ K-PSQI } & \multicolumn{2}{|c|}{ K-BDI } \\
\hline & $\mathrm{r}$ & p-value & $\mathrm{r}$ & p-value \\
\hline Age & 0.062 & 0.547 & 0.045 & 0.662 \\
\hline $\begin{array}{l}\text { Years after the board } \\
\text { certification }\end{array}$ & 0.043 & 0.658 & 0.072 & 0.460 \\
\hline Duty days per month & 0.412 & $<0.001$ & 0.347 & $<0.001$ \\
\hline Working hours per week & 0.431 & $<0.001$ & 0.341 & $<0.001$ \\
\hline $\begin{array}{l}\text { Number of deliveries in the } \\
\text { last month }\end{array}$ & 0.374 & $<0.001$ & 0.610 & $<0.001$ \\
\hline Hours of sleep & -0.434 & $<0.001$ & -0.439 & $<0.001$ \\
\hline K-ISI & 0.734 & $<0.001$ & 0.704 & $<0.001$ \\
\hline K-ESS & 0.501 & $<0.001$ & 0.682 & $<0.001$ \\
\hline Sex, male & 0.132 & 0.179 & 0.126 & 0.202 \\
\hline STOP $>2$ & 0.300 & 0.002 & 0.350 & $<0.001$ \\
\hline Forms of employment & 0.114 & 0.242 & 0.124 & 0.202 \\
\hline $\begin{array}{l}\text { More than one cup of coffee } \\
\text { a day }\end{array}$ & 0.052 & 0.598 & 0.064 & 0.515 \\
\hline $\begin{array}{l}\text { Alcohol ingestion more than } \\
\text { once a week }\end{array}$ & 0.046 & 0.645 & -0.025 & 0.801 \\
\hline Currently smoking & 0.157 & 0.111 & 0.150 & 0.127 \\
\hline Previous illness & 0.154 & 0.115 & 0.154 & 0.114 \\
\hline Medication & 0.047 & 0.634 & 0.056 & 0.570 \\
\hline $\begin{array}{l}\text { Ready-diagnosed sleep } \\
\text { disorder }\end{array}$ & 0.099 & 0.313 & 0.133 & 0.175 \\
\hline
\end{tabular}

K-: Korean version of, PSQI: Pittsburg sleep quality index, BDI: Beck Depression Inventory-2, ISI: insomnia severity index, ESS: Epworth Sleepiness Scale, STOP: an acronym Snoring, Tiredness, Observed apneas, and high blood Pressure.

Table 4. Multiple regression analysis of Korean version of Beck Depression Inventory-2

\begin{tabular}{|c|c|c|c|c|c|}
\hline \multirow[t]{2}{*}{ Regression } & \multirow[t]{2}{*}{$\beta$} & \multirow{2}{*}{$\begin{array}{c}\text { Standardized } \\
\beta\end{array}$} & \multirow[t]{2}{*}{$\mathrm{p}$-value } & \multicolumn{2}{|c|}{$\begin{array}{c}95 \% \text { confidence } \\
\text { interval }\end{array}$} \\
\hline & & & & Low & Upper \\
\hline Constant & -1.953 & & 0.246 & -5.278 & 1.371 \\
\hline K-PSQI & 1.486 & 0.492 & $<0.001$ & 1.074 & 1.898 \\
\hline $\begin{array}{l}\text { Number of } \\
\text { deliveries in the } \\
\text { last month }\end{array}$ & 0.199 & 0.453 & $<0.001$ & 0.139 & 0.259 \\
\hline
\end{tabular}

Adjusted $\mathrm{R}^{2}=0.605, \mathrm{p}<0.001$, age, sex, years after the board certification, duty days per month, working hours per week, number of deliveries in the last month, K-PSQI, Korean version of insomnia severity index, Korean version of Epworth Sleepiness Scale. K-PSQI: Korean version of Pittsburg sleep quality index. 
Table 5. Multiple regression analysis of Korean version of Pittsburg sleep quality index

\begin{tabular}{|c|c|c|c|c|c|}
\hline \multirow[t]{2}{*}{ Regression } & \multirow[t]{2}{*}{$\beta$} & \multirow{2}{*}{$\begin{array}{c}\text { Standardized } \\
\beta\end{array}$} & \multirow[t]{2}{*}{$\mathrm{p}$-value } & \multicolumn{2}{|c|}{$\begin{array}{c}\text { 95\% confidence } \\
\text { interval }\end{array}$} \\
\hline & & & & Low & Upper \\
\hline Constant & 4.450 & & $<0.001$ & 3.504 & 5.396 \\
\hline K-BDI & 0.219 & 0.661 & $<0.001$ & 0.168 & 0.269 \\
\hline
\end{tabular}

Adjusted $\mathrm{R}^{2}=0.431, \mathrm{p}<0.001$, age, sex, years after the board certification, duty days per month, working hours per week, number of deliveries in the last month, K-BDI, Korean version of insomnia severity index, Korean version of Epworth Sleepiness Scale. K-BDI: Korean version of Beck Depression Inventory-2.

Table 6. Multivariate logistic regression of Korean version of Beck Depression Inventory-2

\begin{tabular}{lccc}
\hline & OR & $95 \%$ CI & p-value \\
\hline Constant & 0.003 & & $<0.001$ \\
$\begin{array}{l}\text { Number of deliveries } \\
\text { in the last month }\end{array}$ & 1.088 & $1.041-1.138$ & $<0.001$ \\
K-PSQI & 1.496 & $1.193-1.877$ & $<0.001$ \\
\hline
\end{tabular}

Adjusted for age, sex, years after the board certification, duty days per month, working hours per week, number of deliveries in the last month, K-PSQI, Korean version of insomnia severity index, Korean version of Epworth Sleepiness Scale.

K-PSQI: Korean version of Pittsburg sleep quality index, OR: odds ratio, CI: confidence interval.

Table 7. Multivariate logistic regression of Korean version of Pittsburg sleep quality index

\begin{tabular}{lccc}
\hline & OR & $95 \%$ CI & p-value \\
\hline Constant & 0.068 & & $<0.001$ \\
K-BDI & 1.156 & $1.090-1.227$ & $<0.001$ \\
\hline
\end{tabular}

Adjusted for age, sex, years after the board certification, duty days per month, working hours per week, number of deliveries in the last month, K-BDI, Korean version of insomnia severity index, Korean version of Epworth Sleepiness Scale.

$\mathrm{K}-\mathrm{BDI}$ : Korean version of Beck Depression Inventory-2, OR: odds ratio, $\mathrm{CI}$ : confidence interval.

\section{DISCUSSION}

South Korea faced a low birthrate crisis. South Korea's total fertility rate fell from 1.05 in 2017 to 0.98 in 2018 [19]. Moreover, "preliminary results of birth-death statistics for 2019" stated that South Korea's total fertility rate hit an all-time low again in 2019: 0.92 [20]. Since 2018, South Korea is the only country with a birthrate of less than 1.0 in the OECD! It is a crucial issue in South Korea, and various attempts have been made by the government for several years to overcome this issue. However, there is little research on or support for obstetricians, who plays a vital role in all processes of pregnancy and delivery. Besides, because of low medical costs, high intensity, and legal disadvan- tages, obstetricians in South Korea are increasingly struggling [21]. Hence, it is necessary to examine the psychiatric state of obstetricians in South Korea.

Excessive working hours and accumulated fatigue are well known to increase the risk of negative consequences. This study showed the working environment of obstetricians in South Korea. The upper limit on working hours (52 hours per week) is enforced in South Korea; however, this act does not cover medical doctors, and some obstetricians in South Korea have excessive work hours. In this study, a South Korean obstetrician has a long working time, of approximately 69 hours, although we could not identify a causal relationship between working hours per se and quality sleep. Japanese obstetricians work about 49 hours for women and 55 hours for men [22]. A study from the United States reported that a third of the members of the American College of Obstetricians and Gynecologists had depression [23]. Of the obstetricians who participated in this study, 27.3\% had suffered from depression at some time, $34.3 \%$ had had depression the year before, and $16.5 \%$ of obstetricians were depressed at the time of the study. A Japanese study reported that $8.4 \%$ of doctors specialized in obstetrics and gynecology suffer from depression [22], and the factors related to depression are workload, lower satisfaction with social support, and longer working hours. In this study, the average score of depression did not reach the cut-off value, but approximately $42 \%$ of obstetricians had clinically significant score in the depression scale. We demonstrated the depression is affected by the sleep quality and the number of deliveries, but is not affected by working hours. That is, sleep quality is more important than the absolute number of working hours, which suggests the psychological pressure of delivery on the obstetrician. Conversely, poor sleep quality was estimated at approximately $42 \%$, of which the causal factor was depression. The risk of depression increased by $8.8 \%$ as another monthly delivery was performed. In addition, an increase of one point in K-PSQI increased the risk of depression by $49.6 \%$. Conversely, when K-BDI increased by 1 point, the risk of poor sleep quality increased by $15.6 \%$. The worse the sleep quality, and the more frequent the deliveries, the more depressed the obstetrician is.

There are several limitations. First, since this is a cross-sectional study, we cannot suggest a management strategy for the depression or poor sleep quality of the obstetricians. Second, we could not identify the direction of causality, but could only estimate it by comparing the magnitude of the odds ratios. However, it is clear that depression and sleep quality interact with each other.

The pregnant woman, the baby, and the obstetrician share the process of pregnancy and delivery. Nonetheless, there has never been any policy for or research on obstetricians in South Korea. To the best of our knowledge, this is the first study to investigate the subjective psychiatric state, such as depression and sleep status, of board-certified obstetricians in South Korea. Obstetri- 
cians usually make decisions during intensive monitoring, but sometimes a sudden need for delivery may occur. Doctors have been tending their patients as best they could in their respective fields. As with other majors, obstetrics also has an emergency or treatment burden and concerns about medical disputes. The depression of pregnant women is in the spotlight of obstetricians, but the depression of obstetricians is at a blind spot. The obstetrician's labor is related to the woman's labor. Further prospective longitudinal studies involving treatment strategy, such as cognitive behavior therapy or antidepressant trials, would be needed.

\section{Acknowledgments}

The authors wish to thank and acknowledge So-Young Do for her work on data processing.

\section{Conflicts of Interest}

The authors have no financial conflicts of interest.

\section{Authors' Contribution}

Conceptualization: Kim KT, Bae JG. Data curation: all authors. Formal analysis: Kim KT, Cho YW. Investigation: Jang WK, Bae JG. Methodology: all authors. Supervision: Bae JG. Visualization: Kim KT, Cho YW. Writing_original draft: Kim KT. Writing—review \& editing: all authors.

\section{REFERENCES}

1. Leddy MA, Lawrence H, Schulkin J. Obstetrician-gynecologists and women's mental health: findings of the Collaborative Ambulatory Research Network 2005-2009. Obstet Gynecol Surv 2011;66:316-23.

2. Pearlstein T. Depression during pregnancy. Best Pract Res Clin Obstet Gynaecol 2015;29:754-64.

3. Patel UK, Zhang MH, Patel K, Malik P, Shah M, Rasul BM, et al. Recommended strategies for physician burnout, a well-recognized escalating global crisis among neurologists. J Clin Neurol 2020;16:191-201.

4. Rotenstein LS, Torre M, Ramos MA, Rosales RC, Guille C, Sen S, et al. Prevalence of burnout among physicians: a systematic review. JAMA 2018;320:1131-50.

5. Pulcrano M, Evans SR, Sosin M. Quality of life and burnout rates across surgical specialties: a systematic review. JAMA Surg 2016;151: 970-8.

6. Kang SH, Boo YJ, Lee JS, Han HJ, Jung CW, Kim CS. High occupational stress and low career satisfaction of Korean surgeons. J Korean Med Sci 2015;30:133-9.
7. Smith RP. Burnout in obstetricians and gynecologists. Obstet Gynecol Clin North Am 2017;44:297-310.

8. Vetter MH, Salani R, Williams TE Jr, Ellison C, Satiani B. The impact of burnout on the obstetrics and gynecology workforce. Clin Obstet Gynecol 2019;62:444-54.

9. Bianchi R, Schonfeld IS, Laurent E. Physician burnout is better conceptualised as depression. Lancet 2017;389:1397-8.

10. Bianchi R, Schonfeld IS, Laurent E. Burnout-depression overlap: a review. Clin Psychol Rev 2015;36:28-41.

11. Bianchi R, Schonfeld IS, Laurent E. Burnout or depression: both individual and social issue. Lancet 2017;390:230.

12. Lancet T. Physician burnout: let's talk. Lancet 2017;389:1370.

13. Nakagawa K, Yellowlees PM. The physician's physician: the role of the psychiatrist in helping other physicians and promoting wellness. Psychiatr Clin North Am 2019;42:473-82.

14. Center C, Davis M, Detre T, Ford DE, Hansbrough W, Hendin H, et al. Confronting depression and suicide in physicians: a consensus statement. JAMA 2003;289:3161-6.

15. Lim SY, Lee EJ, Jeong SW, Kim HC, Jeong CH, Jeon TY, et al. The validation study of Beck Depression Scale 2 in Korean version. Anxiety and Mood 2011;7:48-53.

16. Sohn SI, Kim DH, Lee MY, Cho YW. The reliability and validity of the Korean version of the Pittsburgh sleep quality index. Sleep Breath 2012; 16:803-12.

17. Cho YW, Song ML, Morin CM. Validation of a Korean version of the insomnia severity index. JClin Neurol 2014;10:210-5.

18. Cho YW, Lee JH, Son HK, Lee SH, Shin C, Johns MW. The reliability and validity of the Korean version of the Epworth Sleepiness Scale. Sleep Breath 2011;15:377-84.

19. Kown J, Yeung J. South Korea's fertility rate falls to record low [cited 2019 Nov 14]. Available from: https://edition.cnn.com/2019/08/29/ asia/south-korea-fertility-intl-hnk-trnd/index.html.

20. Statistics_Korea. Preliminary results of birth death statistics for 2019 [cited 2020 Mar 19]. Available from: https://kostat.go.kr/portal/korea/ kor_nw/1/2/3/index.board?bmode $=$ read $\& b S e q==\& a S e q=380865 \& p a$ geNo $=1$ \&rowNum $=10$ \&navCount $=10 \&$ currPg $==\&$ searchInfo $==\& \mathrm{~s} T$ arget $=$ title\&sTxt $==$.

21. Kim TH, Lee HH, Kim JM. Legal liability in South Korea. Arch Gynecol Obstet 2015;291:1191.

22. Sugiura-Ogasawara M, Suzuki S, Kitazawa M, Kuwae C, Sawa R, Shimizu Y, et al. Career satisfaction level, mental distress, and gender differences in working conditions among Japanese obstetricians and gynecologists. J Obstet Gynaecol Res 2012;38:550-8.

23. Morgan MA, Schulkin J. Obstetrician-gynecologists and self-identified depression: personal and clinical. Depress Anxiety 2006;23:83-9. 